\title{
UN GRAN SEÑOR MEDIEVAL: DON JUAN MANUEL
}

\author{
Gregorio Sánchez Doncel
}

Es nuestro propósito en esta evocación del Séptimo Centenario del nacimiento de don Juan Manuel, analizar las posesiones que el insigne prócer medieval consiguió reunir. Haremos particular detenimiento en aquellas tierras situadas en la demarcación eclesiástica de la Diócesis de Sigüenza, división geográfica entonces comúnmente aceptada.

Dejamos a los especialistas el estudio de don Juan Manuel como escritor; tampoco intentamos introducirnos en el misterioso mundo tan contradictorio de su espíritu, ni seguiremos paso a paso las vicisitudes de su vida, por demás interesante, fiel exponente de aquel siglo XIV tan convulsivo e inquieto, ni le estudiaremos como valeroso guerrero frente a sus rivales ya del campo cristianos, ya de la frontera musulmana, en la que por cuestiones pesonales de lastimado honor tan corto lucimiento consiguió alcanzar.

Al estudio de las posesiones que constituyeron su rico patrimonio, añadiremos al fin la referencia cinegética que dedicó a estas mismas tierras seguntinas en su «Libro de la Caza».

Huérfano de padre a los dos años, heredó de su progenitor el infante don Manuel extensas propiedades dispersas por la geografía 
castellana, recibidas por su padre de manos del rey de Castilla Afonso el Sabio, su generoso hermano. En el transcurso de su vida amplió don Juan Manuel la herencia con diversas posesiones adquiridas por los medios a su alcace, consciente del imperativo feudad de todo señor que de tal se preciare, de acrecentar y extender su nombre y linaje perpetuándolo en el tiempo a través de su descendencia.

Cuando murió era tan poderoso, que podría mantener a su costa, sin ayuda del rey, cerca de 1.000 caballos e «ir desde el reino de Navarra hasta el de Granada durmiendo cada noche en villa propia cercada o en castillo propio».

En tierras del Duero contaba con Peñafiel, donde erigió formidable castillo sobre alto cerro, acorazada fortaleza dominadora y amenazadora. En tierras toledanas poseía la villa de Escalona, donde nació el 6 de mayo de 1282. En lo que es hoy provincia de Cuenca, llegó a poseer los lugares de Alarcón, Cuenca, Garcı Muñoz y su castillo, Huete, Iniesta y la mitad de Los Hinojosos. En la actual de Abacete, enlazando aquellas tierras con las más meridionales, los lugares de Almansa, Jorquera, Hellín y Tobarra. En la de Alicante, además de esta ciudad, Aspe, Elda, Elche, Monóvar, Novelda, Santa Pola, Sax y Villena. Por último, en tierras murcianas, Cartagena, Librilla, Lorca, Molina la Seca y Yecla.

En tierras seguntinas, no por herencia, sino por compra, Alcocer, Azañón, Cifuentes, Galve, Hita, Palazuelos, Salmerón, Trillo, Val de San García y Viana.

Esta larga lista de sus posesiones no ha de considerarse exhaustiva, pues en los documentos se citan otros lugares de menor importancia que también poseyó.

\section{ESCUDO DE DON JUAN MANUEL}

«Manueles es escudo cuarteado

y dos brazos con alas con espadas

están en cada cuarto colorado, las alas de amarillo muy pintadas, y en cada cuarto blanco, un león doblado. Autor destas familias muy honradas fue don Manuel, infante, atrás tornando un hijo del rey Santo, don Fernando. 


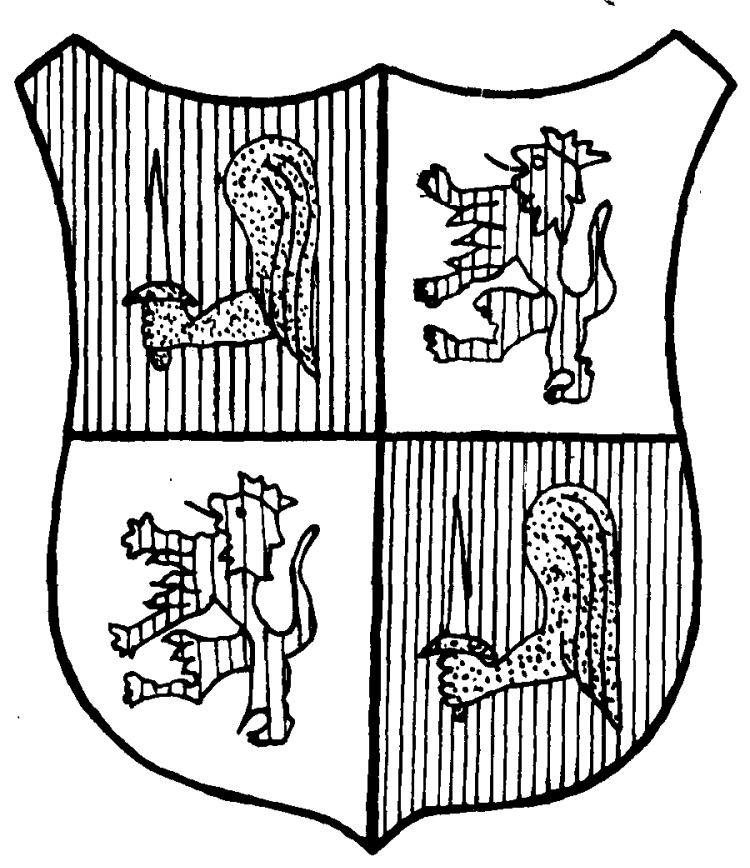

Luis Zapata, en su "Carlos Famoso». Incluido en la Historia de la ciudad de Guadalajara, por Alonso NUÑEZ DE CASTRO, Madrid, Pablo de Val, 1653, p. 173.

El escudo está tomado del respaldo de unas sillas del coro bajo de la Catedral de Sigüenza, fabricadas por Martín Vandoma y añadidas a las del conjunto coral obra del cardenal don Pedro González de Mendoza. Las sillas fueron mandadas hacer por don Juan Manuel, obispo de Sigüenza, (1574-1579), hijo de don Lorenzo Manuel y doña Juana de la Cerdi, señores de Cevico de la Torre y de Belmonte de Campos, en la provincia de Palencia.

El escudo de los Manueles, $t$ ambién se ve en el interior del muro de la entrada de la Iglesia de Janta María de Elche.

\section{I) LA FAMILIA DE DON JUAN MANUEL}

Del matrimonio de Fernando III el Santo con doña Beatriz de Suabia le nacieron siete hijos: Alfonso X el Sabio, que heredó la co- 
rona (1252-1284), Fadrique, Enrique, Sancho, MANUEL, Berenguela, María.

El infante don Manuel, nacido en Carrión y fallecido en Peñafiel el 25-XII-1283, primer señor de Villena, contrajo dos veces matrimonio: Fue su primera esposa doña Constanza de Aragón, hija de Jaime I, de quien tuvo dos hijos: Alfonso, que murió pronto y Violante Manuel, esposa de don Alfonso de Portugal, hermano del rey Dionís, y que fue señora de Elda y Novelda.

Fue su segunda esposa doña Beatriz de Saboya, hija de Amadeo de Saboya y Cecilia de Baucio, su segunda esposa. De este matrimonio tuvo a su vez otros dos hijos: Don JUAN MANUEL, nacido en Escalona el 6-V-1282, segundo señor de Villena, y don Sancho Manuel el Viejo, señor del Infantado de Carrión, a quien heredó su hijo don Juan Sánchez Manuel, conde de Carrión y señor de Calatañazor. A éste le sucede doña Inés Manuel, señora de Castilnuevo y Aguile, casada con don Iñigo López de Mendoza, de quienes fue hijo don Diego Hurtado de Mendoza, primer conde de Priego por su matrimonio con doña Teresa Carrillo, señora de Priego.

Don JUAN MANUEL contrajo matrimonio tres veces. La primera en 1300 , con doña Isabel de Mallorca, hija de Jaime I de Mallorca, fallecida a finales de 1301, de la que no tuvo descendencia.

La segunda el 3-IV-1312 con doña Constanza de Aragón, hija del rey Jaime II. Esta princesa estuvo depositada en el castillo de Villena hasta que alcanzara la edad núbil para contraer matrimonio. Falleció en 1327. De este matrimonio nacieron: doña Constanza, la de los tristes destinos, prometida al rey castellano Alfonso XI, quien la abandonó antes del matrimonio, lo que dio lugar a la rebelión del padre. Casará con don Pedro I de Portugal, quien la pospuso a doña Inés de Castro, bella dama gallega que llevó doña Constanza a Portugal. Otros hijos del segundo matrimonio fueron doña Beatriz y dos niños más que murieron de tierna edad.

La tercera vez que se casó, en 1329, fue con doña Blanca de la Cerda y de Lara, señora de Lara y Vizcaya, hermana del don Juan Núñez de Lara, de cuyo matrimonio nacieron: don Fernando Manuel, heredero de los estados de su padre, tercer señor de Villena. En 1344 concertóse su casamiento con doña Juana Manuel, que heredó los bienes de Lara y Vizcaya, y que casará en secreto con don Enrique de Trastamara, hijo ilegítimo de Alfonso XI con doña Le- 
'onor de Guzmán, el cual llegó a ser rey de Castilla.

Fuera de matrimonio tuvo don Juan Manuel dos hijos ilegítimos: don Sancho Manuel el Mozo, a quien algunos confunden con su tio don Sancho Manuel el Viejo, casado con doña Inés Diaz, hija de don Diego López de Mendoza y doña Urraca Pérez, quienes tuvieron también otra hija, doña María Díaz, casada con don Gonzalo Diaz, hijo de don Pedro Diaz de Toledo, hermano del arzobispo toledano don Gonzalo Diaz Palomeque, cuyos padres fueron don Juan Diaz de Hinojosa y doña Mayor Alvarez.

El otro hijo ilegítimo fue don Enrique Manuel, conde de Cintra en Portugal y de Montealegre, en España.

\section{El obispo don Juan Manuel,} descendiente de su homónimo, en el siglo XVI.

Aparte de los reyes castellanos de la casa de Trastamara, todos ellos descendientes de don Juan Manuel, como originados a través de su nieta doña Juana Manuel, esposa de Enrique II, y por línea recta, creemos digno de mención su homónimo, obispo que fue primero de Zamora (19-1-1565) y luego de Sigüenza (4-VI-1574 hasta su renuncia en 30-I-1679), fallecido el 30-VI-1583. Fueron sus padres don Lorenzo Manuel y doña Juana de la Cerda, señores de Cevico de la Torre y Belmonte de Campos, en la provincia de $\mathrm{Pa}$ lencia.

Hermano suyo fue don Pedro Manuel, que falleció en Madrid en 1578, siendo de la Cámara de Su Magetad y muy apreciado por Felipe II. Su viuda no tuvo sucesión, por lo que los citados señoríos pasaron al obispo de Sigüenza, quien declaró por su heredero al duque de Nájera, don Manrique de Lara en su testamento del ll-IV1583.

Este obispo mandó ampliar con dos sillas el coro bajo de la catedral de Sigüenza, que fueron fabricadas por el insigne escultor y tallista Martin Vandoma, quien dejó grabajo el escudo de los $\mathrm{Ma}$ nueles en cada una de las sillas. Reconstruida la Catedral después de la Guerra Civil como consecuencia de los daños que sufró en su estructura, las sillas fueron colocadas en distinto lugar del que debieron ocupar, que sería el extremo del coro en ambos lados.

MINGUELLA, «Historia de la diócesis de Sigüenza», págs. 271.279.

DHEE, IV, p. 2.476. 


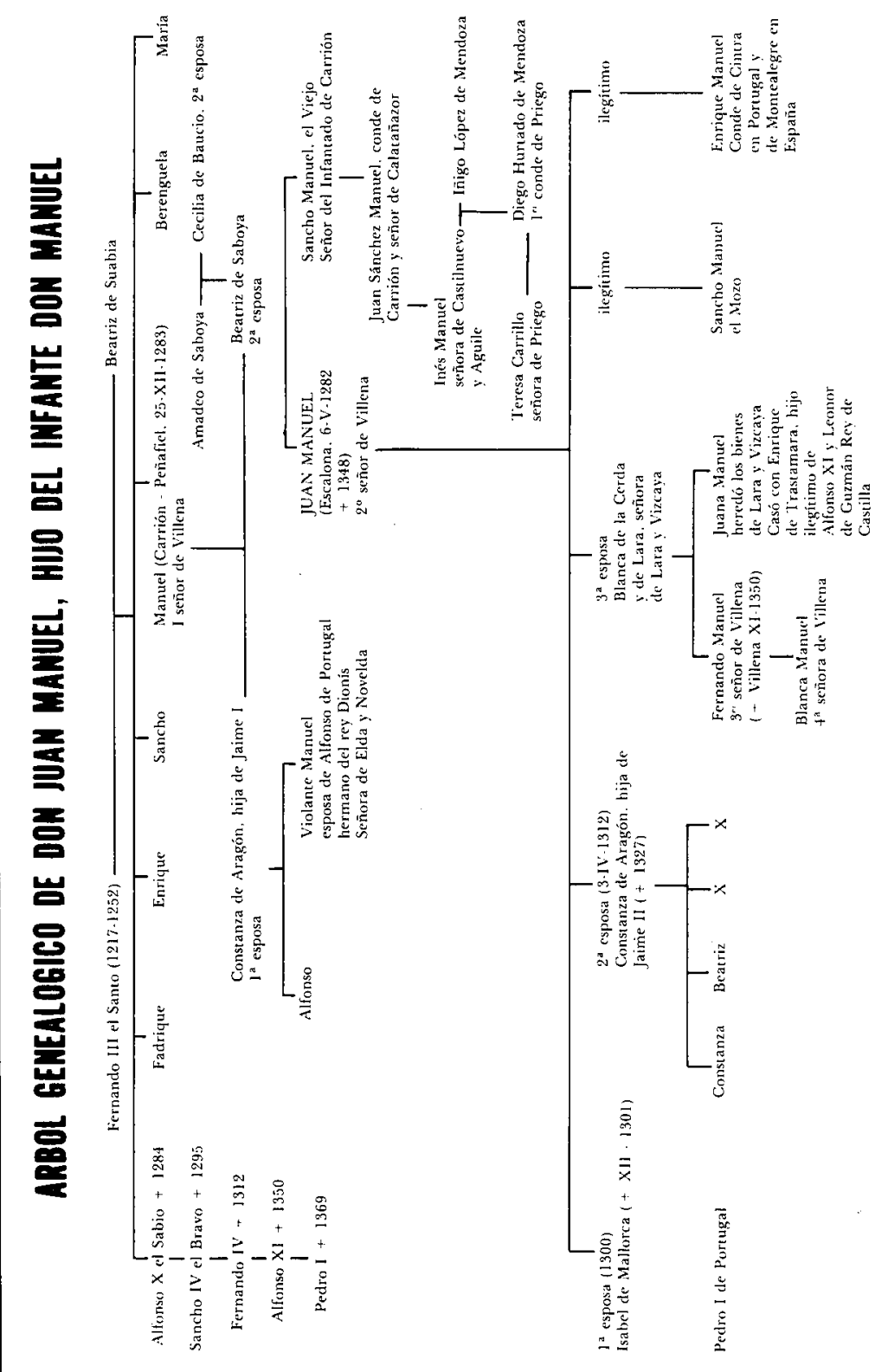




\section{II) EL SEÑORIO DE VILLENA, ¿CASTELLANO O ARAGONES?}

El infante don Manuel, hijo del rey de Castilla Fernando III el Santo, al igual que Alfonso X el Sabio, que sucedió a su padre en el trono, recibió de su hermano, que tanto le apreciaba, numerosas y ricas posesiones de las recién conquistadas tierras del reino de Murcia, entre las cuales figuran los lugares de Villena, Elda, Novelda y Elche, ésta, «con una comarca de lugares que llaman el Alhofra, que fue siempre como reyno e sennorío apartado que nunca obedeció a ningún rey».

Al fallecimiento del infante don Manuel en 1284, recibió su hija doña Violante Manuel los lugares de Elda y Novelda; don Juan Manuel, el mayor de los hijos varones que sobrevivieron, los de Villena y Elche. Mas la posesión de esta herencia no fue siempre quieta y tranquila, como veremos.

Por el tratado de Almizra entre Fernando III y Jaime I, (1244) que señalaba como límite entre ambos reinos una línea que, partiendo de la confluencia de los rios Júcar y Cabriel, pasando por el puerto de Biar, terminaba en Denia, Murcia quedaba para Castilla. El rey moro de Murcia, Mohamed-ben-Alí, se declaró vasallo del rey castellano a cambio de protección, ofreciéndole la mitad de las rentas del reino y permitiendo la ocupación del mismo por tropas castellanas. En 1264 se sublevaron los moros de Murcia, protegidos por el rey de Granada, y Jaime I, su suegro, espontánea y desinteresadamente le ayudó a sofocar la rebelión.

La pretensión de los Infantes de la Cerda al trono de Castilla hizo que Alfonso de la Cerda, buscando el apoyo del rey aragonés, llegase a ceder a Aragón el reino de Murcia, primero a Alfonso III, y, fallecido éste en 1291, a su sucesor Jaime II.

En 1296 Jaime II intentó asignarse el reino de Murcia, entrando en él, pero tuvo que abandonarlo a causa de la peste que asoló el ejército aragonés. El mismo don Juan Manuel hubo de defender a Hellín, que era suyo, con 400 caballos. No por ello desistió de su empeño. Don Juan Manuel, poseedor de gran parte de estas tierras se sentía amenazado. Sin embargo, hubiera salvado estas tierras con sólo reconocer por su señor al aragonés, dejando el vasallaje del castellano. Tan comprometida fue su situación, que pidió al rey de 
Aragón una tregua el 24-IV-1296 antes de determinar, llegando al fin a consentir en perder la juridiscción, que pasó a Aragón, pero salvando la propiedad.

Las villas de Elda y Novelda, que correspondieron a su hermana doña Violante Manuel, al pasar al reino aragonés, fueron permutadas por las de Medellín y Arroyo del Puerco, en Extremadura, como lo prometió el rey castellano don Fernando IV, aunque tanto lo demoró, que hubo de ser presionado por su suegro el rey de Portugal, concediéndoselas al fin en febrero de 1305. Poco después moriría doña Violantes sospechosamente asesinada por su esposo.

A don Juan Manuel le ofreció Fernando IV para compensarle de la pérdida de Elche, la villa de Alarcón. Por el convenio de Ariza del 20-VI-1303, recibió a perpetuidad la villa de Alarcón, cobrase o no cobrase la de Elche.

No poco contribuyó a mantenerse en estos lugares el matrimonio que solicitó del rey de Aragón, Jaime II, aunque comprometiéndose a mantenerse neutral en los asuntos que se relacionaran con Castilla. Ambos esposos recibirían los lugares de Elche, Santa Pola, Aspe, Chinosa, Monóvar y cuanto antes fueron suyo; en rehenes diéronse, Jaime II a don Juan, Alicante, Montova y Biar; don Juan a Jaime II Sax, Jorquera y Villena.

El rey castellano no pudo menos de manifestar su desagrado ante esta actitud de don Juan Manuel, lo que dio motivo a que entonces trataran ambos monarcas de marcar lo límites de sus reinos.

Sometieron sus querellas a juicio de árbitros, obligándose a cumplir lo que determinaran en el asunto. Fueron árbitros el rey de Portugal don Dionís, don Juan y el Obispo de Zaragoza don Jimeno de Luna. Resultado de este arbitraje fue la sentencia de Torrellas del 8-VIII-1304, que comprendía lo siguiente: Que «Cartagena, Guardamar, Alacant, Elche con su puerto de mar, Ella (Elda) e Novella (Novelda), Oriola (Orihuela) con todos sus términos, e pertenencias quantas han e deuen haber así como taja lagua de Segura entra el reino de Valencia entro al más susano cabo del término de Vi!iena, sacada la ciudad de Murcia e Molina la Seca con sus términos, finquen e remangan al rey de Aragón a su propiedad para siempre, así como cosa suya propia con pleno derecho e señorío, salvo que Villena quanto a la propiedad remanga e finque de don Juan Manuel»; quedarían para el rey de Castilla la ciudad de Mur- 
cia, Molina la Seca, Monteagudo, Lorca y Alhama y los demás lugares que tenía el reino de Murcia.

Aunque el dictamen resultaba tan favorable a Aragón como perjudicial para Castilla, a la vista de los anteriores tratados de Tudilen y Almizra, fue ratificado por los monarcas en Campillo al día siguiente, si bien al poco tiempo la ciudad de Cartagena fue adjudicada a Castilla, mediante compensaciones.

El señorío de Villena quedaba, pues, incorporado a Aragón, cuya moneda usaba y con quien libremente comerciaba. Es sin embargo curioso que este doble estado se viera interferido por ambos reinos, que lo deseaban exclusivamente para sí, a pesar del tratado. Mientras los reyes de Castilla confirmaban los fueros y privilegios otorgados a Villena por los reyes castellanos (Sancho IV en 1283; Fernando IV en 1308), los reyes de Aragón concedían privilegios a los de Villena simultáneamente (Jaime II, 1306-1308; doña Leonor, esposa de Alfonso IV, 1331), llegando Alfonso IV a obsequiar a don Juan Manuel con el título de Prícipe de Villena (1331) y Pedro IV a añadir el de Duque de Villena (1336), títulos que nunca ostentó don Juan Manuel en sus documentos, acaso por no herir a los castellanos, contentándose con el que él estimaba del mayor honor, «hijo del infante don Manuel».

Esta continua relación con el reino castellano se manifestó una vez más cuando Enrique II de Castilla en 1369, una vez posesionado del reino castellano, envió a don Juan Sánchez Manuel, primo de su mujer doña Juana Manuel, a quien el señorío villenense pertenecia, a que Villena reconociera por rey de Castilla a don Enrique, a lo que acceden, obteniendo en recompensa nuevos privilegios que la villa solicitó.

\section{III) SENNORIO DE DON JUAN MANUEL EN TIERRAS SEGUNTINAS}

El grueso de las posesiones que don Juan Manuel poseyó en tierras seguntinas fueron adquiridas por él mediante compra que efectuó con la infante doña Blanca que fue abadesa de las Huelgas 
de Burgos hasta su muerte en 1321.

Alfonso X (1252-1284) hizo donación de la villa de Alcocer, con Viana, Azañón, Valdeolivas y otros lugares, junto con los de Cifuentes y Palazuelos, que segregó de la juridicción realenga de Atienza, a doña Mayor Guillén de Guzmán, hermana de don Pedro de Guzmán, Aelantado Mayor de Castilla. De esta dama tuvo el rey, antes de que contrajese matrimonio con doña Violante, una hija, doña Beatriz, esposa que fue de Alfonso III de Portugal. Esta otorgó a Alcocer el fuero de Huete el 22-IV-1281.

De doña Beatriz pasó el señorío a su hija doña Blanca, que fue abadesa de las Huelgas. Según la crónica de Alfonso XI, esta dama determinó vender todas estas posesiones a don Juan Manuel por el año de 1311, bajo ciertas condiciones que don Juan Manuel no pudo cumplir en el plazo fijado. Doña Blanca, en consecuencia, consideró el contrato anulado y determinó efectuar nueva venta de tales posesiones a favor del infante don Pedro, tutor, juntamente con doña María de Molina, del rey niño Alfonso XI.

Indignado don Juan Manuel por esta contrariedad, se sintió tan herido, que llegó a desnaturalizarse de Castilla, promoviendo sangrientas algaradas en Huete, Guadalajara e Hita, que fueron correspondidas a su vez por otras de su contrario en tierras de Escalona, significando con ello don Juan que aquellos lugares seguían siendo suyos.

Al fin en 1316, por mediación del maestre de Calatrava, llegó a un acuerdo con el infante don Pedro, pagando cada uno la mitad de las villas, repartiéndoselas buenamente, correspondiendo a don Juan Manuel Cifuentes, Val de San García y otros lugares; Alcocer, con Viana y Azañón, a don Pedro. Muerto el infante don Pedro juntamente con su hermano don Juan en la vega de Granada en 1319 , otra vez pasaron a su mano todos aquellos territorios, que poseyó hasta su muerte en 1348.

Estos territorios, con el cargo de Adelantado del reino de Murcia, pasaron a su hijo don Fernando Manuel, a la sazón de diez y seis años, que tan sólo pudo disfrutar de ellos dos años, pues fallecía en noviembre de 1350. Hallábase casado con doña Juana de Espina de Romania, hija mayor del infante Ramón Berenguer, conde de Prados y Barón de Entenza, hijo a su vez de Jaime II de Aragón. De este matrimonio hubieron una hija, doña Blanca Manuel, que les heredó, siendo su tutor don Iñigo López de Orozco. Doña Blanca 
murió diez años después, en 1360, siendo todavía niña.

Al fallecer sin descendencia, sus bienes deberian pasar a su tia doña Juana Manuel, desposada en secreto con don Enrique de Trastamara, hijo ilegítimo de Alfonso XI habido de doña Leonor de Guzmán. Sin embargo, se apropió de ellos el rey de Castilla don Pedro. Declarada la lucha fraticida entre el rey don Pedro y su hermano Enrique de Trastamara, éste no dudó en desprenderse de los bienes de su esposa, dándoselos generosamente a don Alfonso de Aragón, hijo del infante don Pedro de Aragón, por voluntaria cesión consentida por doña Juana Manuel, verdadera propietaria de aquellos estados, a cambio de su protección y ayuda en aquella lucha. Ya rey, Enrique le otorgó el título de marqués de Villena, que comprendía, además de las tierras de Villena, las villas de Cifuentes, Salmerón, Alcocer, Escalona, Valdeolivas, Palazuelos.

Don Alfonso de Aragón vendió los lugares de Alcocer, Salmerón y Valdeolivas al mayordomo del rey micer Gómez de Albornoz, casado con doña Constanza de Villena, hija de Sancho Manuel, venta que nuevamente consintió doña Juana, como «heredera de los bienes de mi padre (que Dios perdone)".

Más adelante, hacia el 1395, Enrique III despojó a don Alfonso de Aragón del título y tierras que poseía en Castilla, incorporándolas nuevamente a su real patrimonio. El mismo Enrique III transpasó el señorío de Villena a su hija doña María, con el título de Ducado, título ya antes extendido a favor de don Juan Manuel.

\section{IV) EL SEÑORIO DE CIFUENTES}

Este señorío sigue una línea histórica paralela al de Alcecer, adquirido de doña Blanca, señora de las Huelgas, como consta en documento fechado en Paredes (creemos sea Paredes de Nava) el 12 . $\mathrm{V}-1317$, pues tres días después confirmaba en Palencia a la villa cifontina todos los fueros y privilegios que gozaba.

Con el fin de atraer a su recién adquirida villa nuevos pobladores, con fecha 23-VI-1317 anunciaba la exención de pechos y tributos por tiempo de diez años a cuantos acudieran a vivir en ella. Comenzó la construcción del castillo en 1324. En Cifuentes se encontraba el 21-I-1329, como aparece en el documento de confirma- 
ción de los fueron otorgados. Cerca anduvo el año siguiente de 1330, pues en la villa de Pozancos, próxima a Sigüenza, daba fin a su «Libro de los Estados» el 22 de Mayo.

En 1436 pasaba este señorío a la familia Silva, en la que se fundan título, mayorazgo y estado de Condado de Cifuentes.

Monasterio de Dominicas de San Blas. Extramuros de la villa, menos de media legua, fundó don Juan Manuel un monasterio de religiosas de la Orden de Santo Domingo, que inició allía su vida monacal por el año 1347. "Es casa de mucha religión y santidad». Dotóla don Juan Manuel de muchas rentas. En dicho monasterio se conservaba la cabeza y ciertas canillas de las piernas de San Blas "por quien Dios Nuestro Señor ha hecho grandes milagros», connota la «Relación de Felipe II".

Del monasterio queda como única huella la ermita de la misma advocación de San Blas, construida hacia el siglo XVIII, en término de Gárgoles de Arriba, ya que del antiguo monasterio no queda señal de su emplazamiento.

\section{V) EL SEÑORIO DE TRILLO}

Poseedor don Juan Manuel de la villa de Cifuentes con Val de San García, quiso ampliar su señorío con el lindante lugar de Trillo, situado donde el rio Cifuentes rinde sus aguas en el Tajo.

Compró don Juan Manuel a Trillo hacia el 1322, con sus términos, vasallos, molinos, montes y «fortaleza» por precio de 20.000 maravedís de a diez dineros cada maravedí, a doña Francisca Pérez, casada con don Gil Pérez. De esta venta hicieron carta de ratificación y saneamiento las cuatro hijas de este matrimonio, ya fallecida la madre, que fue la vendedora, el 19 de marzo de 1325 .

En dicho documento se consigna que don Juan Manuel comenzó a construir el castillo de Trillo el 1332, castillo que se alzaba sobre un cerro, a la derecha del rio Cifuentes, en su confluencia con el Tajo.

Incorporado el lugar de Trillo al señorío de Cifuentes, hubo de seguir las vicisitudes del señorío, y así pasó en 1436 a la ilustre fami- 
lia de los Silva, fundadora del condado de Cifuentes, con título, mayorazgo y estado.

CATALINA GARCIA, J. "Memorial Histórico.... t. 41, p. 371

LAYNA SERRANO, F. "Historia de Cifuentes", $2^{\mathrm{a}}$ ed. p. 60-63.

\section{VI) SEÑORIO SOBRE PALAZUELOS}

La villa de Palazuelos, «el Avila de la Alcarria», por su recinto amurallado que la rodea en gran parte de su perímetro, entraba en el lote de doña Blanca la abadesa de las Huelgas. Esta villa, apropiada por el infante don Pedro en su litigio con don Manuel, la vendió al obispo de Sigüenza don Simón Girón de Cisneros el 24-VIII1314, a la sazón canciller del rey.

Que se trata del lugar próximo a Sigüenza es indudable, pues en el documento de compra se dice "que es cerca de Johara (despoblado situado a la izquierda de la carretera de Sigüenza a Berlanga, inmediatamente después de iniciarse el tramo que conduce a Palazuelos y que hoy es imperceptible por ser tierra de labor) y cerca de Carabias, aldea de Atienza e cerca de Sigüenza».

Layna Serrano no debió percibir estas circunstancias, pues llegó a dudar de que don Juan Manuel poseyera algún tiempo este lugar, del que don Juan Manuel afirmó en su Cronicón, que en febrero de 1318 empezó a amurallar Palazuelos: «Era MCCCLV incepit dominus Joannes murare Palacivelos in Februario». Layna llega a pensar se tratara de alguna otra población del mismo nombre, abundante patronímico en Castilla. (1).

Don Juan Manuel no se resignó a reconocer estas sucesivas ventas, que consideró ilegales, pues él pensaba pagar su importe, en cuanto pudiera.

Más tarde Palazuelos pasó a manos de los Mendoza, cuyo escudo figura en sus puertas amuralladas.

\section{VII) EL SEÑORIO SOBRE EL CASTILLO DE GALVE}

En las estribaciones meridionales de la alta Sierra de Ayllón, muralla natural entre las provincias de Guadalajara y las de Segovia y Soria, arriscada dentada de altura media de 1.500 metros, se en-

(1) LAYNA SERRANO, F. "Castillos de Guadalajara», p. 48. 
cuentra el pintoresco pueblo de Galve, apellidado de Sorbe, para distinguirlo de su homónimo de Teruel, a pesar de que no es el Sorbe el que pasa junto a él, sino el arroyo llamado de la Dehesa, que con el de la Romana afluyen al Sorbe, tributario a su vez del Henares.

La cuenca toda del Henares se vio ampliamente jalonada de poderosos castillos, valiosísimos baluartes defensivos frente a aquellas correrías que en la Edad Media agitaban moros y cristianos por aquellas tierras entonces fronterizas.

El castillo de Galve «Castellum Galbi» aparece citado por primera vez en el documento fechado en 1136, al incluir este lugar dentro de la diócesis de Osma, juntamente con otros, en aquel intento de resolver las persistentes querellas que los obispos de Sigüenza, Osma y Tarazona sostenían a favor de sus respectivas diócesis. En el Concilio de Burgos de aquel año (1) presidido por el cardenal Guido se delimitaron sus fronteras. Poco duró esta asignación, pues en 1301 pertenecía la iglesia de Galve al obispado de Sigüenza, a cuya cantoría contribuía con la tercia pontifical íntegra (2).

El término empleado para denominarle "Castellum de Galbi" bien a las claras viene a decirnos que no fue don Juan Manuel quien por primera vez elevara su castillo. La Crónica de Alfonso XI nos dice que don Juan Manuel pasó por su castillo de Galve» con sus gentes al dirigirse a Peñafiel», también de su propiedad, para ayudar a don Juan Núñez de Lara, peligrosamente sitiado por las tropas del rey castellano en su castillo de Lerma, por el año de 1330 . (3).

Alzase el castillo sobre un cerro de 1.400 metros de altitud, dominando amplísimo panorama, lleno de encanto, y a sus pies, 43 metros más abajo el pueblo de Galve, cobijado por su iglesia.

Del antiguo castillo de don Juan Manuel nada queda, nos dice Leyna Serrano. Al hacer las paces con su rey, Alfonso XI, fue don Juan Núñez de Lara quien se ofreció, en nombre de don Juan Manuel, a derribar «el castillo que tenía fecho en Galve», demolición que, así opina Leyna, «se llevó a efecto, pues en documentos poste-

(1) DICCIONARIO DE HISTORIA ECLESIASTICA DE ESPAÑA, I, p. 542. y MINGUELLA, Historia de la Diócesis de Sigüenza, I. p. 358.

(2) MINGUELLA, II, p. 370.

(3) LAYNA SERRANO, F. Castillos de Guadalajara. $3^{\text {a }}$ ed. 107-120. 
riores para nada figura la fortaleza, y de esta no quedaba medio siglo más tarde sino el solar».

El pueblo de Galve, que pasó a la corona, dióselo con todos sus términos y pertenencias en mayorazgo el rey don Pedro el Cruel a Iñigo López de Orozco, tan ligado a don Juan Manuel, el 28-X1354, ya fallecido éste.

En nuestros años se está reconstruyendo por reciente comprador sobre los viejos muros y su sensacional torre interior. Lástima que se encuentre alejado de las más frecuentadas vias de comunicación, pues podría constituir lugar de atracción para aquellos viajeros que gustan de rincones naturales de desacostumbrada belleza. (4).

\section{VIII) EL SEÑORIO DE HITA}

¿Fue alguna vez esta villa de don Juan Manuel?

En documento fechado en Cifuentes por don Juan Manuel en 13III-1339, afirma haber prometido a su hija Constanza, prometida del rey Castellano Alfonso XI, 800.000 maravedís para su casamiento. Al ver que la fecha de este enlace iba dilatándose, temiendo dejar desamparada a su hija, por el constante peligro de muerte a que estaba expuesto su padre, para asegurarle el porvenir le deja diversos castillos y villas de su propiedad, que cita, a la vez que añade los de Galve e Hita, «que vos tendredes del Rey para en vuestra vida, según se contiene en las sus cartas que dél toviemos en esta ra. zón».

Como tal matrimonio no llegó a su efecto, el lugar de Hita no debió pasar a manos de don Juan Manuel ni de su hija doña Constanza (5).

(4) GARCIA MARQUiNA, F. “Guía de los Castillos de Guadalajara”, p. 71-75.

(5) Parece ser que Alvar Fáñez conquistó de los moros la villa de Hita, al mismo tiempo que caían los lugares de Talavera, Madrid, Ribas, Caracuey, Atienza, Riba de Santiuste, Uceda y la propia Guadalajara.

En 1119 Ferrán García y su hermana Estefanía Ermegot recibieron de doña Urraca las villas de Fita y Uceda, que salieron de manos del dominio real. Nuevamente debió pasar a poder real Hita, pues Alfonso X le dio fueros el 24-VII-1256. En 1274 es señora de Hita la infanta doña Berenguela, hija de Alfonso X. A ésta le sucedió en el señorío la infanta doña Isabel, hija de Sancho IV y doña María de Molina. En 1311, siendo regente esta última. don Juan Manuel, rebelde a su rey, arrasa las villas de Hita y Uceda. En 1361 era señor de Hita don Iñigo López de Orozco, mandado matar por el rey Cruel, por haberse pasado al bando de su hermano Enrique. El señorío pasa entonces a don Pedro González de Mendoza, quien en 1380 funda el mayorazgo de Hita. CRIADO DE VAL, M. "Historia de Hita..." pag. 78 . 81 . 


\section{(X) EL DOMINIO DE DON JUAN MANUEL SOBRE MOLINA}

Don Juan Manuel poseyó efectivamente durante algún tiempo, entre otros muchos lugares el de Molina. Mas ¿de qué Molina se trata?

Su hija doña Constanza fue prometida en solemnes esponsales al rey de Castilla Alfonso XI, siendo la novia todavía muy niña, allá por el año 1325. Pero los años iban pasando y el joven rey no parecía muy animado a cumplir su compromiso, como efectivamente lo rompió al casarse con doña María de Portugal. En el interim quiso don Juan Manuel asegurar el porvenir de su hija viendo la dilación del ansiado matrimonio, y estando en Madrid otorgó documento el 6-VI-1331 dando a su hija para cuando él muriese sus castillos y villas de Caracena, Villena, Sax, Almonáster, Yecla, Hellin, Iso, Tobarra, Iniesta, Cifuentes, Palazuelos, Val de San García, et Molina segunt que la ayades e segunt la yo hé e la tiengo y Galve e Hita, "que vos tendredes del rey para en vuestra vida, según se contiene en las sus cartas que dél toviemos en esta razón».

Todavía volvemos a preguntas: ¿de qué Molina se trata?

Citada en el documento anterior a la población de Molina entre las de Cifuentes, Palazuelos, Val de San García, y las de Galve e Hita, todas en tierras seguntinas, parece deducirse lógicamente se trate de Molina de Aragón, señorío que, por otra parte pertenecía al rey novio Alfonso XI, a cuya corona se había incorporado en tiempo de su abuelo Sancho IV, casado con la última șeñora doña Maria de Molina.

Los historiadores de Molina de Aragón no hubieran dejado de consignar este dominio, si hubiera tenido realidad, ya que los molineses hubieran alzado su voz si el dominio hubiera salido algún momento de sus señores naturales, como lo hicieron y violentamente en tiempo de la asignación a don Beltrán Duguesclin y en la del otro don Beltrán de la Cueva (6).

¿Pues qué otra Molina podría ser? Hay otra Molina en tierras murcianas, citada como Molina la Seca, en la sentencia de Torrellas del 8.VIII-1304, en la que intervino don Juan Manuel como compromisario juntamente con el rey de Portugal don Dionís y el arzobispo de Zaragoza don Jimeno de Luna. En dicha sentencia 
quedó asignada a Castilla, juntamente con la ciudad de Murcia, Monteagudo, Lorca y Alhama con los demás lugares que tenía el reino de Murcia.

Esta Molina la Seca no es otra que Molina de Segura, asíllamada por la sequedad de sus tierras, a pesar de que el Segura cruza su término un algo alejado de la villa. No puede ser otra homónima, Molinaseca, en la provincia de León, partido de Ponferrada, más que alejada de los dominios que don Juan Manuel poseyó en la Vieja Castilla (Peñafiel).

Se trata, pues, de Molina de Segura, hasta cuyos términos se extendía el señorío del poderoso señor de Villena.

\section{X) LA CAZA CON HALCONES EN EL OBISPADO DE SIGUENZA EN TIEMPOS DE DON JUAN MANUEL}

El capítulo XII del "Libro de la Caza» que escribiera don Juan Manuel lo dedicó a exponer la geografía de la caza por las diversas tierras castellanas por él recorridas, las más a propósito para el ejercicio cinegético, concretando su descripción en tres regiones, una de las cuales es la que a nosotros nos afecta.

Lo enuncia así:

Capítulo XII. «Muestra qué cazas há et qué logares, para do puede mejor cazar en las tierras do él ha andado.

«Púsolo todo por obispados. Et fabla primeramente... de las ca-

(6) Los señores de Molina de Aragón fueron los siguientes por este orden:

I. El conde don Manrique de Lara, que le dio fueros.

II. Su hijo don Pedro Manrique de Lara, yerno del rey de Navarra.

III. Su segundo hijo don Gonzalo Pérez Manrique.

IV. Su hija Mafalda, casada con don Alonso, hijo de la reina doña Berenguela.

V. Doña Blanca, hija de los anteriores, casada con don Alonso Niño, hijo natural de Al. fonso X el Sabio.

VI. Doña Molina de Aragón, casada con el rey de Castilla Sancho IV, quien lo recibió de su hermana. Entra el señorío en la Corona de Castilla.

Tan sólo en dos ocasiones los reyes castellanos se desprendieron de este señorío con gran disgusto de sus fieles súbditos, otorgándoselo a don Beltrán Duguesclín y al otro don Beltrán de la Cueva. No es para decir la respuesta de los molineses a estas transferencias. La primera vez se pasaron en señal de protesta al reino de Aragón, bajo cuya jurisdicción vivió tan solo veinte años, dando origen al apelativo que viene ostentando de Molina de Aragón. La segunda se enfrentaron al intruso, venciéndole en el Campo de la Matanza y expulsándole del castillo en la noche de Santa Catalina, de donde vino el dicho: «En Santa Catalina, se ganó Molina». ABANADES, Claro, "El Real Señorío de Molina», p. 19.52. 
zas et de los lugares que han para las cazar en el Obispado de Cartagena. Et después en el Obispado de Cuenca. Et después en el Obispado de Çiguenza.

«Et en el Obispado de Osma, Palencia, Burgos, Calahorra, León, Estorga, Zamora, Zalamanca, Avila, Segovia, Toledo, Jahén, Córdoba, Sevilla, en la tierra de la Orden de Santiago, que ellos llaman tierra de León.

Dedica varias páginas al Obispado de Cartagena y Cuenca y termina con el de Sigüenza. Este Obispado, hoy coincidente con los límites de la actual provincia de Guadalajara, desde el año 1955, se internaba en tiempos de don Juan Manuel hacia el norte en las provincias de Segovia y Soria, por lo que habla, al describir esta zona de los territorios de Ayllón, y Berlanga, allende la sierra de Ayllón y los altos de Barahona, hoy fuera de la demarcación provincial de Guadalajara.

«Et dice don Juan que en tierras que él fuese, nunca vio tan buen lugar de todas cazas de falcones, et senaladamente para afitar falcones abaneros et garceros: entre Barahona et Paredes... etc.

«Por ese campo há muchas ánades, et garzas, et grúas, et lechuzas, que es caza muy sabrosa, et muy placentera; al tiempo de verano, que son en la tierra, há muchos alcaravanes et muchos sisones et en todo tiempo muchas liebres et muchas perdices...

«Entre Barahona et Paredes há un arroyo et lagunas en que há muchas ánades et muy buen lugar para las cazar con falcones.

ARROYO CAÑAMARES. El arroyo de Cannamares nasce entre Bannuelos (Bañuelos) et Romanuelos (Romanillos), et cae en Fenares (el rio Henares) deyuso (abajo) de Bragadera: en este arroyo há muchas ánades et garzas. Et desde Torrubia ayuso es de muy buenos pasos: en lo demás es buen lugar para cazar en él con falcones; salvo en cuanto va por grandes pennas.

ARROYO BORNOBA. El arroyo de Bornoba nasce en la fuente que está sobre la laguna de Siente Mohnnos (Somolinos), et entra en Fenares deyuso de Caraceniella: en este arroyo há ánades et garzas, desde Santa María de Sopenna fasta dentro en Fenares, mas en pocos lugares se pueden cazar falcones.

ARROYO DE COGOLLUDO. El arroyo de Cogolludo et entra en Fenares en Fuentiana: en este arroyo há pocas ánades. Pero do las fallan, bien se pueden cazar con falcones.' 
EL RIO SORBE. El arroyo de Sobrel se ayunta de muchos arroyos, dellos que nascen so Catasávalos (Campisábalos y dellos cabe Galve. Et dellos, del un cabo et del otro de Cantalojas et entra en Fenares en Pennahora: en estos arroyos fasta que llegan al Angostura, deyuso de la Puente, que dicen de Valdallo, há muchas ánades et buen lugar para las cazar con falcones. Mas de la Agostura ayuso fasta Belenna non se pueden cazar con falcones. Et desde Belenna fasta do entra en Fenares, há buen lugar para las cazar. Et algunas vegadas recude hi garza.

ARROYO DE GERCADILLO. El arroyo de Certadiello nasce en la Dehesiella de Atienza sobre Torde Rey, et entra en el rio de Aymón (Imón) sobre Sancta María: en este arroyo há parada de ánades et garzas a las veces, et buen lugar para las cazar con falcones, salvo por do va entre pennas.

ARROYO DE RIBA DE SANTIUSTE. El arroyo de la Riba nasce del cerca de Atienza et otra parte dél sobre Paredes, et ayúntase a él el arroyo de Val del Cubo, el otro que se llega a el cabo de la Riba un poco de suso (arriba): en todos estos arroyos há muchas ánades et parade garzas, et en lo demás son en buen lugar para las cazar con falcones. Pero a lugares hay malos pasos et tremedales, et por ese valle a las más veces falla hi un par o dos de grúas de morada; cerca de las salinas de Aymón viene un arroyo en que há muchas ánades para cazar con falcones.

EL RIO SALADO. El arroyo de Rio Salado nasce en la aldea que llega al arroyo de las Saliniellas; há en él ánades a logares, et buen lugar para las cazar con falcones. Et en el arroyo de las Salinas fasta que entra en las Salinas de Boniella, ha muchas ánades: et buen lugar para las cazar con falcones. Los arroyos de Val de Paraiso son bien tres o cuatros et en todos há muchas ánades, et buen lugar para las cazar con falcones, salvo dos que llegan al Carrizal cerca de las Salinas.

RIO HENARES. El rio Fenares nasce sobre Cigüenza cerca de Horna et fasta de yuso de la villa há muchas ánades et parada de garzas, et salvo por do va por hoces et grandes angosturas de pennas, puédense bien cazar con falcones, et ayúntase con Rio Salido en Vaydes, et dende adelante lleva Fenares el nombre, et piérdelo Rio Salido.

ARROYO DE ARAGOSA. El arroyo de Aragosa nasce una par- 
te dél sobre Saúca et la otra parte dél cerca Borjarraval (Bujarrabal) et ayúntase sobre Xodara (Jodra): en estos arroyos há muchas ánades et parada de garzas, et fasta Xodara es buen lugar para las cazar con falcones. Et de Xodara ayuso (abajo) fasta que pasa por la foz de Haragosa, va por muy fuertes lugares, también para cazar, camino para andar.

ARROYO DE VALFERMOSO. El arroyo de Val Fermoso nasce sobre Almodrones (Almadrones) et entra en Fenares deyuso de Sancta María de Sopenna, et há en él pieza de ánades: et el mejor lugar que há para las cazar con falcones es desde Algeziella (Argecilla) fasta cerca de Utande.

ARROYO DE CIFUENTES. El arroyo de Cifuentes nasce en Cifuentes, et entra en el Tajo cerca de la Casa de Crillo (Trillo): en este arroyo et en las lagunas cerca de San Blas há muchas ánades, et parada de garzas, et en lo más há buenos lugares para cazarlas con falcones.

TIERRA DE MEDINA. En tierra de Medina há muchas riberas en que há muchas ánades et partida de garzas et a lugares algunas grúas de morada. Et dice don Juan que non se acuerda de los nombres de los lugares do nascen. Mas la una es un arroyo que pasa por Balbazil, et es buen arroyo de caza. Et el otro que pasa por la Riba de Sant Felices (Saelices) et Tajunna, que nasce sobre Luzón, et el arroyo que pasa cerca de Minno (Miño) et va por el Alcobiella, et va a Calatahojar (Caltojar) do se ayuntan en el arroyo que viene de la Riba Descalote: en todos estos arroyos há muchas ánades et pieza de garzas et como quier que a lugares van por tierra fragosa et hay malos pasos. Pero lo demás todo se caza muy bien con falcones.

TIERRA DE MOLINA. Tierra de Molina, si non es el rio que pasa por Molina: dice don Juan que non sabe él hí buena ribera ninguna, commo quier que le dijeron que contra el campo que había buenas riberas et otro sí que en el rio de Mesa que había muchas garzas.

TIERRAS DE ALMAZAN. Otrosí en tierra de Almazán dice don Juan quel dijeron que había hí pieza de buenas riberas, mas dice que non se le acertó de cazar en ellas. Pues es acabado de contar las riberas que don Juan sabe del Obispado de Cigüenza.

Don Juan Manuel había recorrido una a una las tierras todas de la meseta castellana desde Peñafiel y Escalona, por las de Sigüenza 
y Cuenca hasta las de Villena, recreándose en momentos tranquilos de su ajetreada vida en el noble ejercicio de la caza, lo que le facilitó escribir este libro, en el que volcó todas sus experiencias y conocimientos sobre la materia, pues aparte de los interesantes datos geográficos e hidrográficos que nos ha legado, dio también a conocer muy ampliamente curiosísimos detalles sobre cetrería, lo que ha facilitado, con otros libros similares, recobrar los procedimientos medievales acerca del adiestramiento de los halcones, que teníamos perdidos.

No cabe duda de que la geografía hidrográfica de la antigua diócesis de Sigüenza poco ha cambiado en estos setecientos años transcurridos desde entonces, aunque bien podemos decir que «ha llovido y no poco". La constante erosión originada por los agentes naturales algo habrá modificado, aunque no tanto como la acción del hombre, al introducir en esas riberas y valles el cultivo de los cereales - lo que deteriora el paisaje vegetal-, sustituyéndolo por el bosque de encinas y robles y aun de hayas, pues precisamente en esta septentrional región de la provincia de Guadalajara se. conserva el más meridional de los hayedos de Europa.

En estos últimos años el Servicio de Concentración Parcelaria ha saneado numerosos arroyos con poderosas máquinas, obteniendo a la vez que la eliminación de terrenos anegados, hábitat de estas aves, la desecación para el cultivo de secano.

Hoy no abundan como otrora estas aves, pero todavía esporádicamente aparecen algunos ejemplares, ávida presa de cazadores armados, lo que ha obligado a que recientemente, el 6-11I-1981, el Estado Español promulgara una ley de protección de estas especies en via de extinción, prohibiendo la caza de rapaces e insectívoros, la garza y la grulla, aunque ha dejado en libertad al ánade y al sisón, más abundantes, en determinados días no vedados.

La garza, tímida y recelosa, por ser la más perseguida, es emigrante, inverna de octubre a marzo en Africa y se viene a veranear por toda Europa, junto a las charcas y terrenos pantanosos en busca del sustento que aprende con su largo pico.

El hábitat del ánade o pato es más dilatado, pues a la zona norteafricana de emigración añade el sur asiático, si bien gran parte de la especia se queda en España, así como en Italia o Grecia. Hay zonas de países europeos donde en el buen tiempo se las ve reunidas 
por centenares de miles, ocupando en su extensión los estanques, lagos y pantanosos suelos, ejercitando su incansable voracidad, que no tiene límites.

Las "grúas" o grullas son más bien aves de paso, de muy alto vuelo, que en ocasiones se nos muestran apoyadas en un solo pie. De cuerpo ceniciento y negras las plumas mayores de sus alas, se alimentan asímismo de cereales tiernos, hierbas, guisantes y frutas, alternadas con gusanos, insectos, langostas o saltamontes, grillos, libélulas, ranas y reptiles acuáticos...

El área de dispersión de los sisones, aves del orden de las corredoras, es bastante extenso: Hungría, Francia, Sur de Rusia, Turquía, Grecia, Italia y España; accidentalmente se presenta en Holanda, Bélgica, Alemania e Inglaterra. En nuestra península se encuentra por todas partes, pero en muy pequeña proporción, frecuentando los viñedos, las llanuras y las faldas de las montañas. Por la excelencia de su carne, considerada tan deliciosa como la del faisán, sufre más activa persecución.

No faltan igualmente en verano los alcaravanes - denominación árabe - , aves zancudas de unos 30 ó 40 centímetros de altura, cabeza gruesa, cuello relativamente corto, pico recto y fuerte de tanta longitud como la de su cabeza, sostenida en largas piernas amarillas, el vientre blanco y alas blancas y negras, con el resto de su cuerpo rojo. Dícese de él que en viendo al cazador o ave de rapiña, lanza fuertes chillidos, que alertan y hacen huir a las demás aves que por allí se encuentran, quedándose el alcaraván en peligro, lo que ha dado lugar al dicho: «Alcaraván zancudo: para otros consejo, para tí ninguno». Como ave nocturna, sale por la noche a la caza de insectos, ratones de campo, sapos, ranas, etc. Vive en las estepas de Europa meridional, de Africa y de Asia occidental; no es raro encontrarle en las llanuras de Alemania y Hungría y hasta en el sur de Suecia.

\section{XI) ITINERARIO DE DON JUAN MANUEL}

$\begin{array}{rrrl}1282 & \text { V } & 5 & \text { Escalona. Nacimiento. } \\ 1285 & \text { II } & 11 \text { Soria. Confirma documento de Sancho } \\ & & \text { IV. (12) p. } 190 .\end{array}$


1294 VI

, $\quad$ XI

1295

,"

1296 I

X

1298 III

$1299 \mathrm{X}$

1300 I

" IX

" XII

$1301 \quad$ I

$"$ XII

1302 VIII

1303 III

III

IV

",

V

VI

,"

VII

VII

",

VIII

IX

$\mathrm{X}$
6 Murcia. Adelantado Mayor (4) p. 215.

Primer combate (8) p. 3.

Valladolid. (8) p. 3

Peñafiel. (8) p. 4

Madrid. (8) p. 4

Murcia. (8) p. 6

2 Villena. (17) p. 93

Cuéllar. (8) p. 11

10 Valladolid. Confirma documento de Fernando IV. (12) p. 238

26 Garci Muñoz. (8) p. 239

3 Peñafiel. (8) p. 241

Requena. (8) p. 12

21 Villar del Salsa. (8) p. 244

31 Huete. (8) p. 245. (Con su esposa Isabel)

31 Badajoz. (Acompañando al rey de Castilla. (8) p. 248

Escalona. Allí muere Esabel su esposa.

26 Palencia. (8) p. 254

18 Badajoz. (8) p. 259 (Bedaios por Badaios)

31 San Esteban de Gormaz. (8) p. 264

6 Montalbanejo (Cuenca). (8) p. 265

11 Zafra (Cuenca. (8) p. 273

9 Játiva. (Entrevista con Jaime II). (8) p. 266

15 Cuenca. (8) p. 33

21 Jorquera (Albacete). (8) p. 278

Atienza. (8) p. 33

20 Ariza. (8) p. 281

Teruel. (8) p. 21

2 Zafra (Cuenca). (8) p. 289

15 Confruentes (8) p. 288

20 Zafra (Cuenca). (8) p. 22

Peñafiel. (8) p. 22

Peñafiel. (8) p. 23

2 Hinojosa. (8) p. 293 


\begin{tabular}{|c|c|c|c|}
\hline 1303 & $\mathrm{X}$ & & Jorquera. (8) p. 22 \\
\hline$"$ & $\mathrm{XI}$ & 14 & Fuentes de Alarcón. (8) p. 294 \\
\hline 1304 & II & 19 & Palomares. (8)p. 298 \\
\hline$"$ & IV & 25 & Cueva. (8) p. 301 \\
\hline$"$ & $"$ & & Roa. (8) p. 25 \\
\hline$"$ & VI & 14 & Burgos. (8) p. 304 \\
\hline$"$ & $"$ & 28 & Burgos. (8) p. 304 \\
\hline$"$ & VII & 2 & Burgos. (8) p. 306 \\
\hline$"$ & IX & 12 & Cuenca. (8) p. 306 \\
\hline$"$ & $\mathrm{X}$ & 31 & Huete. (8) p. 307 \\
\hline$"$ & XI & 28 & Escalona. (8) p. 309 \\
\hline$"$ & XII & 14 & Cuenca. (8) p. 311 \\
\hline 1305 & II & 2 & $\begin{array}{l}\text { Guadalajara. (8) p. } 30 \\
\text { Medina del Campo: (8) p. } 30\end{array}$ \\
\hline$"$ & III & & Alarcón. (8) p. 314 \\
\hline$"$ & IV & 3 & Huete. (8) p. 314 \\
\hline$"$ & $\mathrm{~V}$ & 26 & Ramiro (Valladolid). (8) p. 317 \\
\hline$"$ & VI & 13 & Bujalaro (Guadalajara). (8) p. 320 \\
\hline$"$ & $"$ & 16 & Brihuega. (8) p. 318 \\
\hline$"$ & VIII & 11 & $\begin{array}{l}\text { Verdel Pinero (Verdelpino de Huete). } \\
\text { (8) p. } 320\end{array}$ \\
\hline$"$ & IX & 1 & Huete. (8) p. 323 \\
\hline$"$ & $"$ & 5 & Huete. (8) p. 324 \\
\hline 1306 & II & 13 & Alarcón. (8) p. 327 \\
\hline$"$ & III & 9 & Garci Muñoz. (8) p. 330 \\
\hline$"$ & $"$ & 13 & Garci Muñoz. (8) p. 330 \\
\hline$"$ & IV & I & Valencia. (8) p. 32 \\
\hline$"$ & $"$ & 17 & Valencia. (8) p. 331 \\
\hline$"$ & V & 2 & Ayora (Valencia). (8) p. 333 \\
\hline$"$ & V & 9 & Cuenca. (8) p. 334 \\
\hline$"$ & $"$ & 13 & Garci Muñoz. (8) p. 32 \\
\hline$"$ & $"$ & 15 & Cuenca. (8) p. 332 \\
\hline$"$ & $"$ & 26 & Cuenca. (8) p. 334 \\
\hline " & $"$ & 28 & Valencia. (8) p. 32 \\
\hline$"$ & VI & 1 & $\begin{array}{l}\text { Masarabuleque (Mazarulleque), } \\
\text { (Cuenca). (8) p. } 335\end{array}$ \\
\hline$"$ & VI & 16 & Atienza. (8) p. 337 \\
\hline$"$ & $"$ & 19 & Atienza. (8) p. 337 \\
\hline$"$ & IX & & Cadahabro? (8) p. 340 \\
\hline
\end{tabular}




\begin{tabular}{|c|c|c|c|}
\hline 1306 & $\mathrm{XI}$ & 14 & Escalona. (8) p. 341 \\
\hline 1307 & I & 30 & Petrel. (8) p. 345 \\
\hline$"$ & II & 4 & Murcia. (8) p. 346 \\
\hline$"$ & 6 & & Murcia. (8) p. 346 \\
\hline$"$ & $"$ & 8 & Murcia. (8) p. 346 \\
\hline$"$ & ", & 11 & Murcia. (8) p. 347 \\
\hline$"$ & $"$ & 26 & $\begin{array}{l}\text { Villena. (17) p. } 93 \text { y } 216 \text { (documento), } \\
\text { (8) p. } 348\end{array}$ \\
\hline$"$ & IV & 9 & Huete. (8) p. 349 \\
\hline$"$ & V & 25 & Peñafiel. (8) p. 350 \\
\hline$"$ & VIII & 26 & Atienza. (8) p. 351 \\
\hline 1308 & II & 19 & Sitio de Moya. (8) 352 y 328 \\
\hline$"$ & III & 16 & $\begin{array}{l}\text { Villena. (17) p. } 93 \text { y } 216 \text { (documento) } \\
\text { y (8) p. } 353 .\end{array}$ \\
\hline$"$ & $"$ & 19 & Chinchilla. (8) p. 353 \\
\hline$"$ & V & 2 & $\begin{array}{l}\text { Valladolid (Confirma documento de } \\
\text { Fernando IV). (17) p. } 218\end{array}$ \\
\hline$"$ & $"$ & 11 & Valencia. (8) p. 358 \\
\hline$"$ & $"$ & 28 & Burgos. (8) p. 356 \\
\hline " & VII & 17 & Burgos. (8) p. 360 \\
\hline$"$ & $\mathrm{X}$ & 27 & Atienza. (8) p. 361 \\
\hline 1309 & II & 28 & $\begin{array}{l}\text { Madrid. (Primeras cortes allí habida. } \\
\text { (8) p. } 363\end{array}$ \\
\hline$"$ & $X$ & 22 & Sitio de Algeciras. (8) p. 367 \\
\hline 1310 & V & 7 & Valencia de Don Juan. (8) p. 367 \\
\hline$"$ & VI & 19 & Brihuega. (8) 377 \\
\hline$"$ & & & Córdoba. (8) p. 40 \\
\hline$"$ & VII & 18 & Huete. (8) p. 381 \\
\hline 1311 & III & 6 & Peñafiel. (8) p. 388 \\
\hline$"$ & $"$ & 25 & Becerril de Campos. (8) p. 389 \\
\hline$"$ & $\mathrm{~V}$ & 15 & Atienza. (8) p. 391 \\
\hline " & $\mathrm{V}$ & 25 & Atienza. (8) p. 392 \\
\hline$"$ & VI & 26 & Peñafiel. (8) p. 395 \\
\hline$"$ & VIII & 10 & Huete. (8) p. 396 \\
\hline$"$ & $\mathrm{XI}$ & 4 & Peñafiel. (8) p. 400 \\
\hline 1312 & II & 11 & $\begin{array}{l}\text { Atienza. (8) p. } 405 \text { (error en la fecha } \\
\text { del libro). }\end{array}$ \\
\hline$"$ & III & 3 & Valdejudíos. (8) p. 406 \\
\hline$"$ & IV & 7 & Almansa. (8) p. 407 \\
\hline
\end{tabular}




\begin{tabular}{|c|c|c|c|}
\hline 1312 & VII & 1 & Garci Muñoz. (8) p. 409 \\
\hline$"$ & $"$ & 3 & Garci Muñoz. (8) p. 409 \\
\hline ", & $"$ & 21 & Alarcón. (8) p. 408 \\
\hline " & IX & 10 & Murcia. \\
\hline$"$ & IX & 17 & Murcia. (8) p. 417 \\
\hline$"$ & $\mathrm{X}$ & 8 & Cuenca. (8) p. 413 \\
\hline " & $\mathrm{XII}$ & 26 & Cañamares (Guadalajara). (8) p. 419 \\
\hline 1313 & I & & Madrid. (8) p. 422 \\
\hline$"$ & II & 4 & Santa María del Tiemblo. (8) p. 424 \\
\hline$"$ & II & 20 & Toro. (8) p. 427 \\
\hline$"$ & III & 31 & Valladolid. (8) p. 427 \\
\hline$"$ & IV & 13 & Villena. \\
\hline$"$ & $\mathrm{~V}$ & 23 & Grijota (Palencia). (8) p. 429 \\
\hline 1314 & III & 1 & Villena. (17) p. 93 y (8) p. 442 \\
\hline$"$ & $\mathrm{~V}$ & 1 & Villena. (17) p. 93 \\
\hline$"$ & $"$ & 9 & Villena. (17) p. 93 \\
\hline$"$ & VII & 7 & $\begin{array}{l}\text { Valladolid. (Confirma documento de } \\
\text { Alfonso XI. (13) p. } 412 \text {. }\end{array}$ \\
\hline$"$ & IX & 17 & Salmerón. (8) p. 458 \\
\hline$"$ & $"$ & 27 & Garci Muñoz. (8) p. 458 \\
\hline 1315 & & & Uclés. (8) p. 36 \\
\hline 1316 & & & Villena. (17) p. 93 \\
\hline$"$ & II & & Cuéllar. (11) p. 59 \\
\hline 1317 & $\mathrm{~V}$ & 12 & $\begin{array}{l}\text { Paredes de Nava. (11) p. } 58 \text { y (7) p. } \\
361\end{array}$ \\
\hline$"$ & $"$ & 15 & $\begin{array}{l}\text { Palencia. (11) p. } 59,65 \text { y } 284 \\
\text { (documento) y (7) p. } 361\end{array}$ \\
\hline$"$ & VI & 23 & $\begin{array}{l}\text { Cifuentes. (11) p. } 60 \text { y } 283 \\
\text { (documento) y (7) p. } 362\end{array}$ \\
\hline$"$ & IX & 4 & Villena (17) p. 93 \\
\hline 1320 & IV & 4 & Talavera de la Reina. (8) p. 487 \\
\hline$"$ & VII & 18 & Peñafiel. (8) p. 489 \\
\hline$"$ & $\mathrm{X}$ & 10 & Segovia. (8) p. $49 \mathrm{l}$ \\
\hline "' & $\mathrm{XI}$ & 30 & Córdoba. (8) p. 493 \\
\hline 1321 & III & 20 & $\begin{array}{l}\text { Madrid. (10) p. } 81 \text { y } 116 \text { (documento) } \\
\text { y (13) p. } 493\end{array}$ \\
\hline 1325 & IX & 5 & Villaóñez. (8) p. 512 \\
\hline$"$ & $"$ & 27 & Valladolid. (8) p. 514 \\
\hline$"$ & $\mathrm{X}$ & 13 & Peñafiel. (8) p. 516 \\
\hline
\end{tabular}




\begin{tabular}{|c|c|c|c|}
\hline 1325 & $\mathrm{X}$ & 14 & Peñafiel. (8) p. 518 \\
\hline 1326 & III & 10 & Alcalá de Henares. (8) p. 525 \\
\hline ", & IV & 12 & Escalona. (8) p. 526 \\
\hline$"$ & & 14 & Escalona. (8) p. 527 \\
\hline$"$ & VII & 20 & $\begin{array}{l}\text { Medina del Campo. (Confirma docu- } \\
\text { mento de Alfonso XI). (12) p. } 254 \\
\text { Guadalhorca. Vence a Ozmin, caudillo } \\
\text { del rey de Granada. }\end{array}$ \\
\hline 1327 & I & 2 & Garci Muñoz. (8) p. 533 \\
\hline " & II & 28 & Montalbo. (8) p. 536 \\
\hline$"$ & III & 15 & Montalbo. (8) p. 550 \\
\hline$"$ & IV & 2 & Garci Muñoz. (8) p. 538 \\
\hline$"$ & VII & 15 & Garci Muñoz. (8) p. 545 \\
\hline " & IX & 15 & Garci Muñoz. (8) p. 559 \\
\hline$"$ & $\mathrm{XI}$ & & Escalona. (8) p. 37 \\
\hline$"$ & XII & 16 & Zafra (Cuenca). (8) p. 552 \\
\hline$"$ & $"$ & 17 & Montalbo. (8) p. 550 \\
\hline 1328 & I & 23 & Garci Muñoz. (8) p. 559 \\
\hline$"$ & III & 3 & Villena. (17) p. $93,(8)$ p. 561 \\
\hline$"$ & $"$ & 22 & Garci Muñoz. (8) p. 563 \\
\hline$"$ & IV & 8 & Huste. (8) p. 566 \\
\hline$"$ & VI & 12 & Garci Muñoz. (8) p. 571 \\
\hline 1329 & I & 2 & $\begin{array}{l}\text { Cifuentes. (11) p. } 65 \text { y } 286 \\
\text { (documento) y (7) p. } 363\end{array}$ \\
\hline 1330 & I & 2 & Jérica. (8) p. 579 \\
\hline "' & V & 22 & $\begin{array}{l}\text { Pozancos (Junto a Sigüenza, da fin al } \\
\text { Libro de los Estados. (8) p. } 166\end{array}$ \\
\hline$"$ & $\mathrm{X}$ & 10 & Chinchilla. (8) p. 585 \\
\hline 1331 & II & 18 & Fuente del Olmo. (8) p. 589 \\
\hline 1332 & I & 3 & Garci Muñoz. (8) p. 594 \\
\hline ", & $"$ & 29 & $\begin{array}{l}\text { Valladolid. (Confirma documento de } \\
\text { Alfonso XI (13) p. } 494\end{array}$ \\
\hline$"$ & VIII & 17 & Garci Muñoz. (8) p. 594 \\
\hline 1333 & III & 17 & Cifuentes. (8) p. 598 \\
\hline 1334 & I & 23 & Villena. (17) p. 93 \\
\hline " & III & 7 & Castelfabit. (8) p. 604 \\
\hline$"$ & IV & 22 & Peñafiel. (8) p. 611 \\
\hline$"$ & V & 14 & Peñafiel. (8) p. 611 \\
\hline
\end{tabular}




\begin{tabular}{|c|c|c|c|}
\hline 1335 & VI & 11 & Salmerón. (8) p. 168 \\
\hline$"$ & IX & 28 & $\begin{array}{l}\text { Valladolid. (Confirma documento de } \\
\text { Alfonso XI). (12) p. } 257 \text {. }\end{array}$ \\
\hline 1336 & II & 20 & $\begin{array}{l}\text { Valladolid. (Confirma documento de } \\
\text { Alfonso XI. (13) p. } 512\end{array}$ \\
\hline$"$ & VI & 13 & Alarcón. (8) p. 621 \\
\hline ", & VII & 30 & Garci Muñoz. (8) p. 622 \\
\hline 1337 & $\mathrm{X}$ & & Daroca. (8) p. 112 \\
\hline 1339 & IV & 6 & $\begin{array}{l}\text { Madrid. (11) p. } 67 \text { y } 286 \text { (documento) } \\
\text { y (7) p. } 364\end{array}$ \\
\hline$"$ & $\mathrm{~V}$ & 15 & Cifuentes \\
\hline$"$ & $"$ & 31 & Hizo testamento. (11) p. 74 \\
\hline 1340 & IV & 10 & Lechón (Zaragoza). (8) p. 631 \\
\hline$"$ & $\mathrm{X}$ & 30 & Batalla del Salado \\
\hline 1341 & III & 1 & Villena. (17) p. 93 y 227 (documento) \\
\hline 1342 & I & 24 & $\begin{array}{l}\text { Villanueva de don Fernando. } \\
\text { (Fundada por don Juan Manuel en } \\
\text { tierras de Murcia. (8) p. } 113 \text { y } 640 \text {. }\end{array}$ \\
\hline 1344 & III & 26 & Toma de Algeciras. (11) p. 74 \\
\hline & VIII & 14 & Sevilla. (11) p. 74 (hizo testamento) \\
\hline 1345 & IV & 7 & Peñafiel. (8) p. 643 \\
\hline 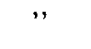 & $"$ & 10 & Peñafiel. (8) p. 671 \\
\hline 1347 & IV & 19 & $\begin{array}{l}\text { El Alamo. (11) p. } 70 \text { y } 289 \\
\text { (documento) }\end{array}$ \\
\hline " & VI & 20 & $\begin{array}{l}\text { Cifuentes. (11) p. } 291 \text { (documento) y } \\
\text { (7) p. } 365\end{array}$ \\
\hline 48 & IV, & & Córdoba o Murcia. Fallecimiento. \\
\hline
\end{tabular}

\section{BIBLIOGRAFIA}

(1) ABANADES LOPEZ, Claro. “El Real Señorío Molinés (Compendio de su historia)».

(2) AZUAR RUIZ, R. "Castellología medieval alicantina: área meridional". Alicante, Gráficas Diaz, 1981.

(3) CRIADO DE VAL, Manuel "Historia de Hita y su Arcipreste». Madrid, Artes Gráf. Encinas, 1976.

4) DICCIONARIO ENCICLOPEDICO HISPANO-AMERICANO. (DEHA).

5) DICCIONARIO DE HISTORIA ECLESIASTICA DE ESPAÑA.(DHEE). 
6) GAIBROIS DE BALLES'TEROS, Mercedes. «El príncipe don Juan Manuel y su condi. ción de escritor». Discurso leido ante el Instituto de España en la Fiesta del Libro el 17. IV. 1943. Madrid, Imp. Magisterio Español, 1945.

(7) GARCIA LOPEZ, Juan Catalina. "Memorial Histórico Español», t. XLI. Biografia y estudio crítico». Zaragoza, Tip. La Academia, 1932.

(8) JIMENEZ SOLER, Andrés. "Don Juan Manuel». Biografía y estudio crítico. Zaragoza. Tip. La Academia, 1932.

(9) LAYNA SERRANO, F. "Castillos de Guadalajara», $3^{3}$ edición Madrid. Imp. T.P.A. 1962.

(10) LAYNA SERRANO, F. "Los conventos antiguos de Guadalajara». Mdarid. Aldus S.A. 1943.

(11) LAYNA SERRANO, F. “Historia de Cifuentes», $2^{a}$ ed. Guadalajara. Gráficas J.C. J. 1978.

(12) LOPERRAEZ CORVALAN, Juan. "Descripción Histórica del Obispado de Osma». Madrid, Ed. Turner, 1978.

(13) MINGUElla Y ARNEDO, Toribio. "Historia de la Diócesis de Sigüenza y de sus obispos". Madrid, Tip. "Revista de Archivos, Bibliotecas y Museos, tomo I1. 1912.

(14) NUN̄EZ DE CASTRO, Alonso. "Historia de la ciudad de Guadalajara». Madrid. Pablo de Val, 1653.

(15) PEREZ ARRIBAS. Andrés. "Alcocer. Historia y Arte». Guadalajara. edit. OPE. 1974.

(16) SANCHEZ DONCEL. Gregorio. "Alcocer. (Guadalajara)". En "Remanso", Zaragoza, $\mathrm{n}^{\circ} 45$, mayo-junio 1968.

(17) SOLER GARCIA, José Maria, "La relación de Villena de 1575», $3^{\mathrm{a}}$ ed. Alicante. 1974. 